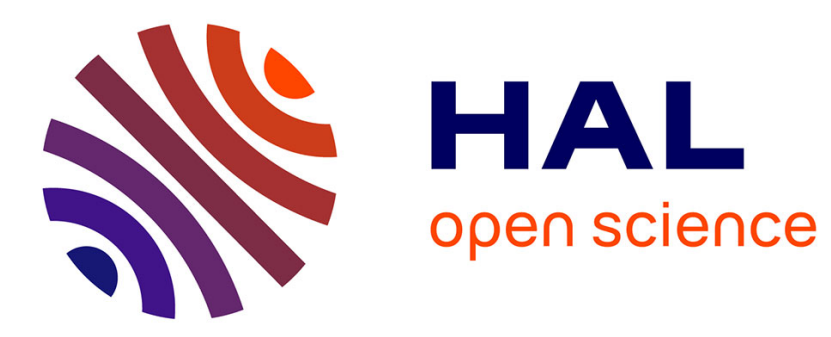

\title{
pH-operated hybrid silica nanoparticles with multiple H-bond stoppers for colon cancer therapy
}

Christophe Théron, Audrey Gallud, Simon Giret, Marie Maynadier, Damien

Grégoire, Pierre Institut Chirurgie Visc|rale, Clinique Mutualiste Beau-Soleil

Puche, Eric Jacquet, Georges Pop, Olivia Sgarbura, Virginie Bellet, et al.

\section{To cite this version:}

Christophe Théron, Audrey Gallud, Simon Giret, Marie Maynadier, Damien Grégoire, et al.. pHoperated hybrid silica nanoparticles with multiple H-bond stoppers for colon cancer therapy. RSC Advances, 2015, 5, pp.64932-64936. 10.1039/c5ra09891b . hal-01214697

\section{HAL Id: hal-01214697 \\ https://hal.science/hal-01214697}

Submitted on 15 Feb 2022

HAL is a multi-disciplinary open access archive for the deposit and dissemination of scientific research documents, whether they are published or not. The documents may come from teaching and research institutions in France or abroad, or from public or private research centers.
L'archive ouverte pluridisciplinaire HAL, est destinée au dépôt et à la diffusion de documents scientifiques de niveau recherche, publiés ou non, émanant des établissements d'enseignement et de recherche français ou étrangers, des laboratoires publics ou privés. 

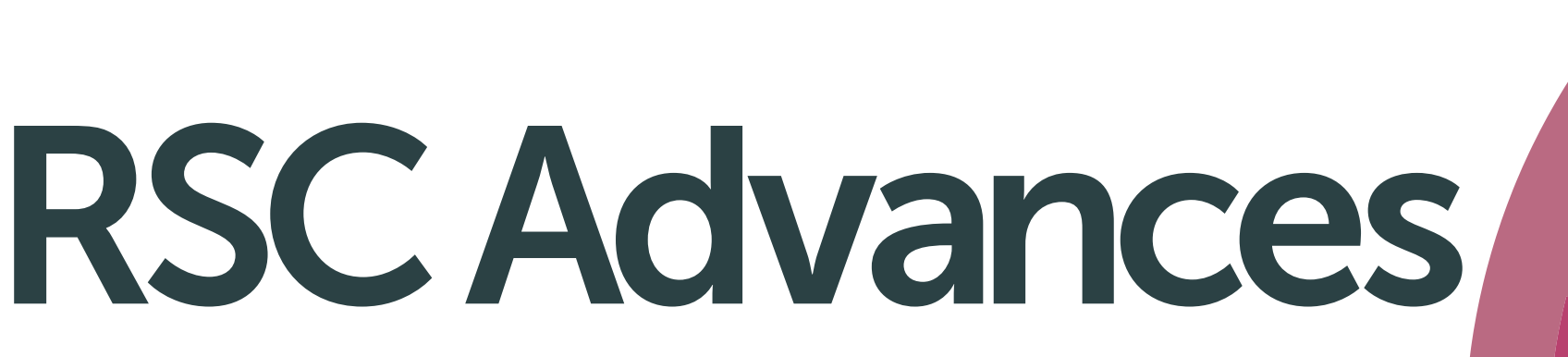

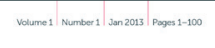

\section{RSC Advances}

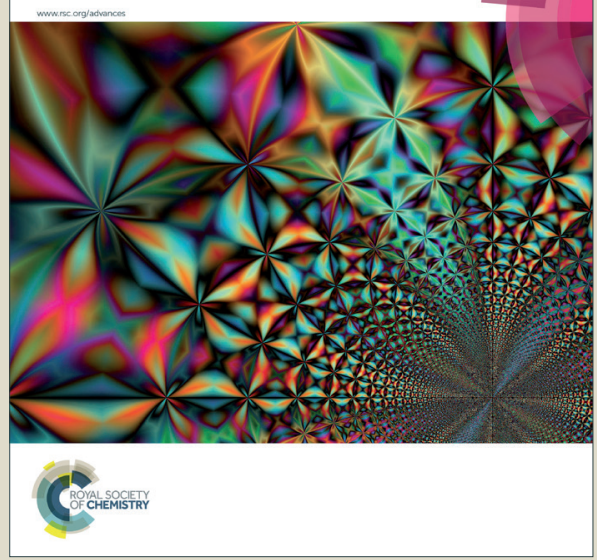

This is an Accepted Manuscript, which has been through the Royal Society of Chemistry peer review process and has been accepted for publication.

Accepted Manuscripts are published online shortly after acceptance, before technical editing, formatting and proof reading. Using this free service, authors can make their results available to the community, in citable form, before we publish the edited article. This Accepted Manuscript will be replaced by the edited, formatted and paginated article as soon as this is available.

You can find more information about Accepted Manuscripts in the Information for Authors.

Please note that technical editing may introduce minor changes to the text and/or graphics, which may alter content. The journal's standard Terms \& Conditions and the Ethical guidelines still apply. In no event shall the Royal Society of Chemistry be held responsible for any errors or omissions in this Accepted Manuscript or any consequences arising from the use of any information it contains. 


\section{Journal Name}

\section{COMMUNICATION}

\section{pH-operated Hybrid Silica Nanoparticles with Multiple H-bond Stoppers for Colon Cancer Therapy}

Received 00th January 20xx, Accepted 00th January 20xx

DOI: $10.1039 / \times 0 \times x 00000 x$

www.rsc.org/

\author{
C. Théron, ${ }^{a, g_{\dagger}}$ A. Gallud,${ }^{b}+$ S. Giret, ${ }^{a}$ M. Maynadier, ${ }^{c}$ D. Grégoire, ${ }^{d}$ P. Puche, ${ }^{e}$ E. Jacquet, ${ }^{e}$ G. Pop, ${ }^{e} O$. \\ Sgarbura, ${ }^{f}$ V. Bellet, ${ }^{b}$ U. Hibner, ${ }^{d}$ J. I. Zink, ${ }^{g^{*}}$ M. Garcia, ${ }^{b}$ M. Wong Chi Man, ${ }^{a}$ C. Carcel, , ${ }^{*}$ and M. \\ Gary-Bobo,
}

The transport of anticancer molecules by nanoparticles has shown great promise in terms of bioavailability, concentrating drugs in the tumor area and minimizing drug side effects. Here, we report the high efficiency of pHoperated hybrid silica nanocarriers for colon cancer therapy. These silica nanoparticles carry the drugs which are tightly held by cyanuric acid as a new type of stopper. The latter can be autonomously removed upon acidic medium allowing a direct drug release inside the cancer cells. Importantly, the proof of concept was established by ex vivo experiments using primary cell cultures from patient biopsies.

The World Health Organization published in GLOBOCAN data that colorectal cancer is the third most common cancer in men and the second one in women. ${ }^{[1]}$ The first treatment option is the surgical resection of the primary tumor. However, there is an important mortality rate in older patients, in the post-surgery year (about $50 \%) .{ }^{[2]}$ In addition, surgery is often followed by adjuvant chemotherapy (oxaliplatin or 5-FU) to eradicate eventual micrometastases. Then, in the most advanced cases such as metastatic diseases, combination regimen could be used, involving several drugs like 5-FU, folic acid and irinotecan (also named camptothecin (CPT)). Even if these strategies are significantly efficient to treat tumors and metastases, they are often followed by vital organ function decline, particularly for older patients. ${ }^{[3]}$ In these conditions, we can imagine that a nanosystem allowing the confinement and the targeting of the chemotherapy could be of particular interest to treat tumors and to decrease the spreading of

\footnotetext{
a.Institut Charles Gerhardt Montpellier, UMR 5253 CNRS-Université Montpellier-ENSCM, 8 Rue de l'École Normale, 34296 Montpellier, France. E-mail: carole.carcel@enscm.fr

${ }^{b}$ Institut des Biomolécules Max Mousseron de Montpellier, UMR 5247 CNRS-Université Montpellier-ENSCM, Bâtiment (E), Faculté de Pharmacie, 15 avenue Charles Flahault BP14491, 34093 Montpellier, France.E-mail: magali.gary-bobo@inserm.fr

c.NanoMedSyn, 15, avenue Charles Flahault BP14491, 34093 Montpellier, France.

d.Institut de Génétique Moléculaire de Montpellier, UMR 5535, CNRS, Université Montpellier, 1919 route de Mende, 34293 Montpellier, France.

e. Clinique Beau-Soleil, 119 Avenue de Lodève, 34070 Montpellier, France.

f.Institut régional du Cancer Montpellier, Chirurgie A2, 208 Avenue des Apothicaires 34298 Montpellier, France.

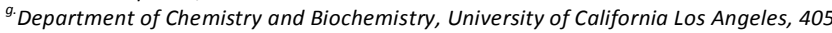
Hilgard Avenue, Los Angeles, CA 90095 (USA).E-mail: zink@chem.ucla.edu + These two authors contributed equally to this work.

Electronic Supplementary Information (ESI) available: [details of any supplementary information available should be included here]. See DOI: 10.1039/x0xx00000x
}

drugs in healthy organs. ${ }^{[4]}$

We have previously reported the use of molecular recognition to design $\mathrm{pH}$-operated stoppers as autonomous drug delivery systems. ${ }^{[5]}$ In one case, a nucleobase (uracyl moieties) bonded to $\beta$ cyclodextrin was used as snap top which were linked via a single molecular recognition pattern of three $\mathrm{H}$-bonds to a triazine stalk grafted on MCM-41 type mesoporous silica nanoparticles. ${ }^{[6,7]}$ Although these nanocarriers proved to be efficient drug delivery systems, a major drawback stems from the fact that the stopper could only be synthesized in a very low yield after a long reaction time ( $5 \%$ in 2 weeks). Our strategy to optimize the use of nanocarriers holding molecular recognition sites prompted us to take benefit from the commercially available and cheap cyanuric acid (CA) which can play the role of the snap top. Indeed, we recently showed that CA could form stable complex with triazines in bulk hybrid silica materials at neutral $\mathrm{pH}$ and can be cleaved under slightly acidic $\mathrm{pH}^{[8,9]}$ Thus using $\mathrm{CA}$ would then lead to a new system avoiding tedious synthetic steps. In addition, it can be subject to a complexation by three molecular recognition patterns which may allow a more gradual (controlled) release. Moreover, it has been demonstrated that the nanopores with a $2 \mathrm{~nm}$ diameter ordered two-dimensional hexagonal nanoparticles (NPs) could be large enough to contain dyes and drugs and small enough to be blocked by organic molecules. ${ }^{[10,11]}$

The capping strategy and $\mathrm{pH}$-controlled release of cargo from a pore are outlined in Scheme 1. The pores should remain closed at blood pH (7.4) and their opening is desired as soon as the nanoparticles are endocytosed in the cancer cells under the acidic $\mathrm{pH}$ of late endosomes and lysosomes (4.5-5). Many groups have reported on $\mathrm{pH}$-responsive silica nanoparticles modified with various gatekeepers ${ }^{[12]}$ which usually do not comply with zeropremature drug release. The NPs presented in this work exhibited a completely non-premature release.

In this investigation, NPs were prepared from a modification of the Stöber process that we have used previously. ${ }^{[5]}$ Cetyltrimethylammonium bromide (CTAB) was used as the surfactant to construct the hexagonal compact porosity with a $\mathrm{N}_{2}$ adsorption-desorption analysis Brunauer, Emmett and Teller (BET) surface area of 1086 $\mathrm{m}^{2} \cdot \mathrm{g}^{-1}$. The average pore size was calculated to be around $49 \AA$. 


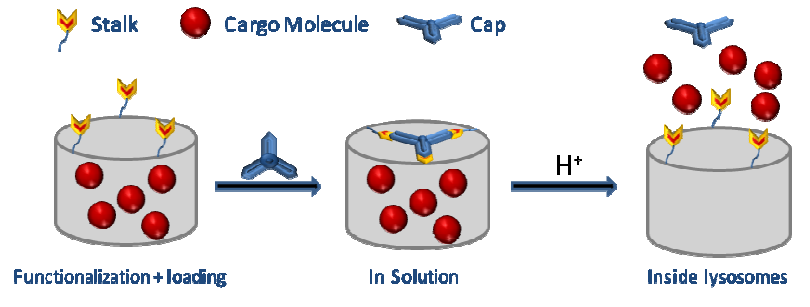

Scheme 1. Functionalization, loading and releasing strategy

These NPs were functionalized with the organosilylated triazinederived stalk (Scheme 2) bearing recognition sites and their physico-chemical properties were fully characterized as reported in a previous study. ${ }^{[5]}$

Then, the NPs were loaded either with propidium iodide (PI) as fluorescent dye to monitor the release experiments, or with the anticancer drug CPT for cancer cell death evaluation. Finally, NPs were capped with the commercially available CA. For accurate release experiments the nanoparticles were carefully washed to ensure the removal of any physisorbed $\mathrm{PI}$ or CPT affording respectively $\mathrm{NP}_{\mathrm{PI}}$ and $\mathrm{NP} \mathrm{P}_{\mathrm{CPT}}$.

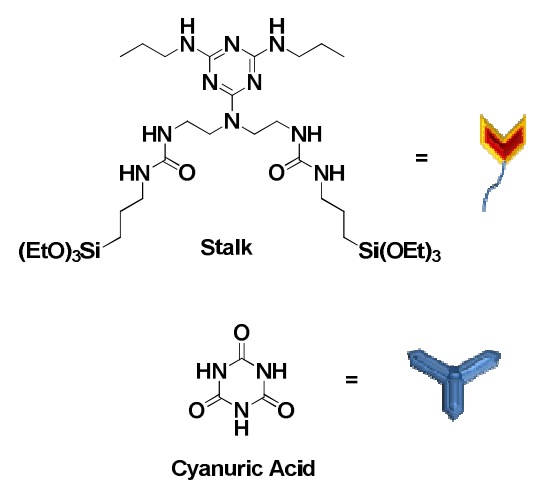

Scheme 2. Stalk and cap molecules

In parallel NPs were prepared without any cargo molecules and were used for blank tests. A theoretical proportion, of 3 stalks for 1 cap, was used to favour a complete complexation of the $3 \mathrm{CO}-\mathrm{NH}-$ CO (ADA) patterns of CA with the NH-CO-NH (DAD) pattern of the triazine stalks. The size of CPT loaded and capped nanoparticles have been examined by both TEM and DLS in different media and monodisperse nanoparticles (100 to $150 \mathrm{~nm}$ ) were observed (Figure 1). The concentration of CPT loaded into $\mathrm{NP}_{\text {CPT }}$ was quantified by UV-Vis assay after acidic treatment for a full uncapping and showed an amount of $40 \mu \mathrm{g}$ of drug per mg of NP (Table S1).

The release of $\mathrm{PI}$ was determined in water at $\mathrm{pH}$ from 4 to 6 to mimic endosomal compartments and $\mathrm{pH} 3$ to evaluate the complete release of the dye. This was monitored continuously by time-resolved fluorescence spectroscopy. $\mathrm{NP}_{\mathrm{PI}}$ were placed in the corner of a cuvette and the surrounding liquid was stirred gently. A probe beam was used to illuminate the liquid above the NPs and to follow the release of the PI molecules in the supernatant as they escaped the nanoparticles.

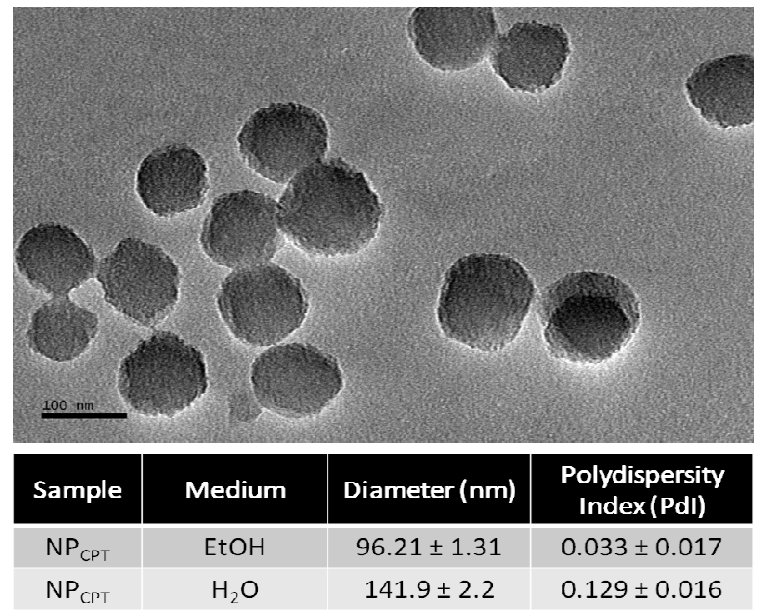

Figure 1. (Top) TEM microscopy imaging of NP $\mathrm{P}_{\text {CPT. }}$. Scale bars $=100 \mathrm{~nm}$. (Bottom) Hydrodynamic size of $\mathrm{NP}_{\text {CPT }}$ in EtOH and deionised $\mathrm{H}_{2} \mathrm{O}$.

To ensure that no $\mathrm{PI}$ release occurred at the beginning of the experiments, the NPs were left at neutral $\mathrm{pH} 7$ for 1 hour before adjusting the solution to the chosen acidic $\mathrm{pH}$. PI was not observed in solution during this first hour implying no premature release of the cargo molecule and demonstrating that the pores remained closed at $\mathrm{pH} 7$ (Figure S1). Additionally, no PI release could be observed at $\mathrm{pH} 6$ as demonstrated by the flat line but it occurred from $\mathrm{pH} 5$ indicating the potential of these systems as an autonomous drug delivery system in cells (Figure 2 ).

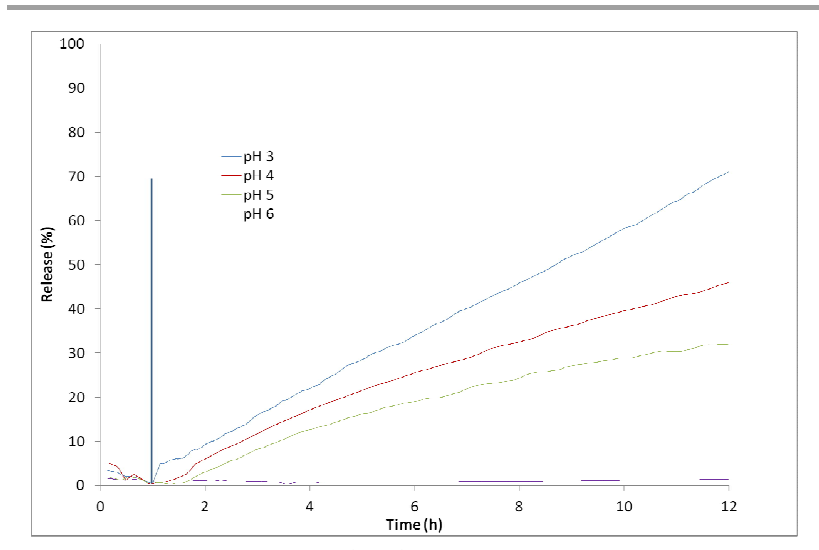

Figure 2. Release experiments of $\mathrm{CA}$ for various $\mathrm{pH}$.

The delivery rate depends directly on the $\mathrm{pH}$ value with higher release rates occurring at higher acidity and in each case the delivery took place gradually.

To demonstrate that NPs were taken up by cells, HCT-116 cells were incubated $20 \mathrm{~h}$ with $40 \mu \mathrm{g} \cdot \mathrm{mL}^{-1}$ of $\mathrm{NP}_{\mathrm{PI}}$ and analyzed by confocal laser scanning microscopy (Figure 3). Co-staining was performed with Hoechst, a blue fluorescent marker of the nucleus, and a green fluorescent (Alexa Fluor 488) plasma membrane dye. $\mathrm{NP}_{\mathrm{PI}}$ red fluorescence demonstrated their intracellular localization. However, the localization in acidic vesicles as lysosomes is the mandatory condition for the opening of the $\mathrm{pH}$-sensitive stoppers and the release of drugs. Thus, the lysosomal localization of $\mathrm{NP}_{\mathrm{Pl}}$ was 
investigated by using a green lysotracker. The merged picture shows a high level of yellow points corresponding to the colocalization of green lysosomes and red $\mathrm{NP}_{\mathrm{PI}}$ which demonstrates that the cellular internalization is by the endolysosomal pathway.
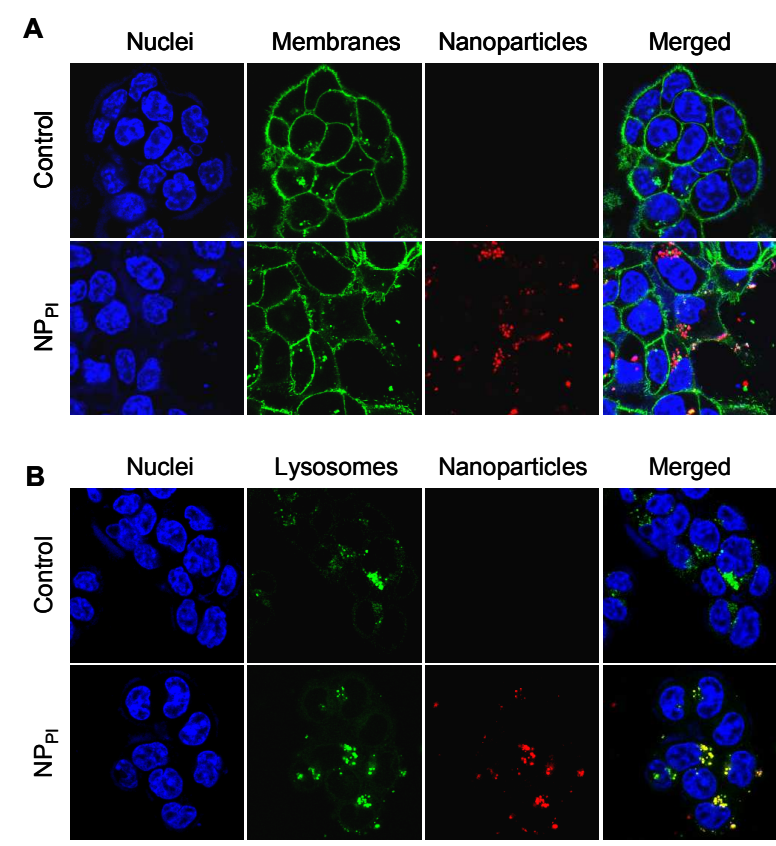

Nanoparticles

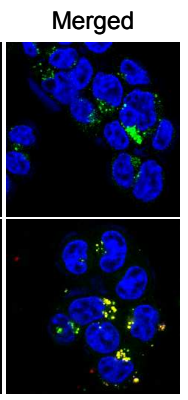

Figure 3. Confocal imaging on living HCT-116 cancer cells incubated $20 \mathrm{~h}$ with $\mathrm{NP}_{\mathrm{Pl}}$ at $40 \mu \mathrm{g} \cdot \mathrm{mL}^{-1}$ with (A) plasma membranes staining and (B) lysosomes staining.

The next step was to prove that these NPs could be used for drug delivery. For this, the cytotoxicity of $\mathrm{NP}_{\mathrm{CPT}}$ was established on HCT116 cells and Figure $4 \mathrm{~A}$ shows a strong cytotoxic activity of $\mathrm{NP}_{\mathrm{CPT}}$ on these cells with an $\mathrm{IC}_{50}$ close to $1 \mu \mathrm{g} \cdot \mathrm{mL}^{-1}$. In contrast, $100 \%$ of normal human fibroblasts survived to the same treatment conditions. This suggests that normal cells are much less sensitive to the $\mathrm{NP}_{\mathrm{CPT}}$ than colorectal cancer cells (Figure S2). This difference could be due to an increase in the internalization of such nanoparticles of about $130 \mathrm{~nm}$ diameter, by cells with a high capacity of endocytosis (close to phagocytosis) like cancer cells. These results demonstrate the CPT efficiency for colorectal cancer treatment and the better delivery of this drug in tumorigenic cells by using these self-operating nanocarriers. ${ }^{[13-15]}$

To confirm the higher accumulation of NPs in cancer cells than in normal ones, a quantification of $\mathrm{NP}_{\mathrm{PI}}$ internalization between non tumorigenic (BMEL) and tumorigenic (BMEL-Ras) hepatic progenitors was realized by using flow cytometer. ${ }^{[16]}$ Data showed that tumorigenic cells internalized 2 fold more NPs that non tumorigenic ones (Figure $4 \mathrm{~B}$ ). The fact that this experiment was realized on a same cell line with or without tumorigenic properties contributes also to demonstrate the higher endocytosis capacity of cancer cells than normal ones. A kinetic study was realized and confirmed the 2 fold higher internalization of tumorigenic cells after short or long incubation time (Figure S3).
Control experiments were realized to validate the absence of toxicity induced by corresponding concentrations of CA and empty NPs (Figure S4).

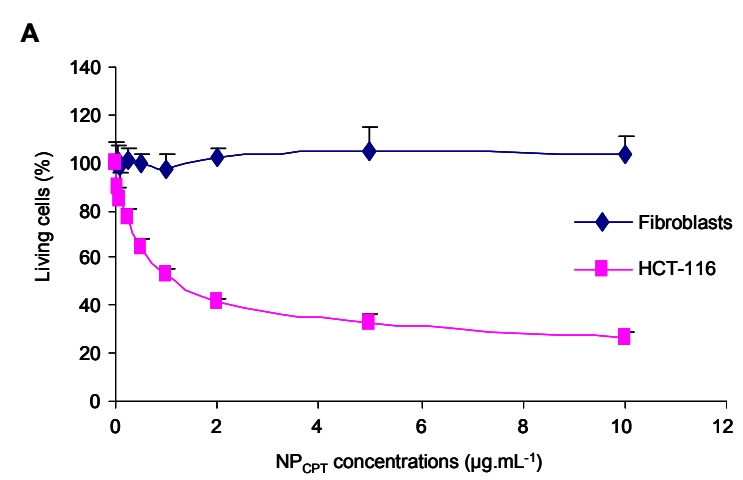

B

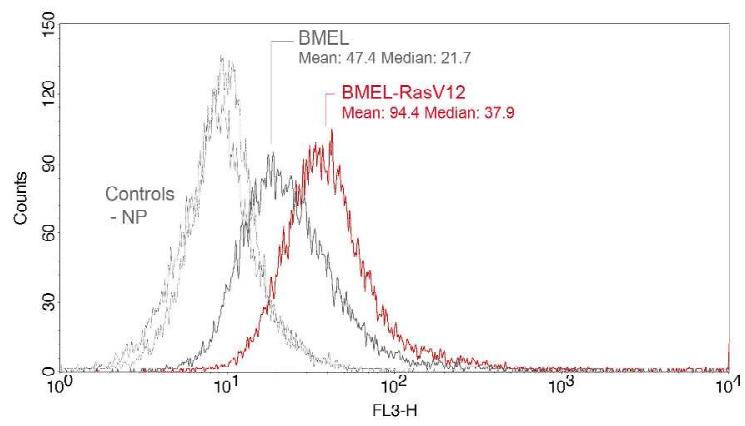

Figure 4. (A) Cell viability of HCT-116 colorectal cancer cells and normal fibroblasts treated for $72 \mathrm{~h}$ with increasing doses of $\mathrm{NP}_{\mathrm{CPT}}\left(0\right.$ to $10 \mu \mathrm{g} \cdot \mathrm{mL}^{-1}$ ) and submitted to MTT assay as described in Experimental Section. Values are mean \pm SD of 3 experiments and are expressed as $\%$ of control cells treated with vehicle alone. (B) Fluorescence quantification by FACSCalibur of non tumorigenic (BMEL) and tumorigenic (BMEL-Ras) hepatic progenitors incubated $20 \mathrm{~h}$ with $\mathrm{NP}_{\mathrm{Pl}}\left(40 \mu \mathrm{g} \cdot \mathrm{mL}^{-1}\right)$. Results reproduced in 4 independent experiments with 3 independent sets of cell lines.

Based on these encouraging results, the therapeutic efficiency of these NPs was investigated on human primary cells from clinical specimens of colorectal cancers, obtained in accordance with the code of ethics of the world medical association. For this, the biopsies collected were treated in order to dissociate cells and allow their growth in vitro. Even if tumor biopsies contain not only cancer cells but also a part of normal cells, we can suppose that cancer cells represent a majority of adherent cells to plastic. Indeed, some control experiments using colorectal normal tissues were attempted but normal cells could not be successfully cultured (data not shown). The internalization of NPs in primary cells was analyzed by confocal microscopy on living cells and we observed a huge internalization of $\mathrm{NP}_{\mathrm{PI}}$ which were co-localized with lysosomes (Figure 5A).

Then, the cytotoxic effect of $\mathrm{NP}_{\mathrm{CPT}}$ was studied on primary culture cells. During their growing, these cells form colonies. ${ }^{[17,18]} \mathrm{We}$ measured the number and the size of colonies treated with NP $P_{C P T}$ during 8 days. The size of colonies treated with 5 or $10 \mu \mathrm{g} \cdot \mathrm{mL}^{-1}$ decreased to $50 \%$ and $80 \%$, respectively. In contrast, in control cultures, colonies treated with the vehicle alone showed a linear 
increase of about $40 \%$ (Figure 5B). This strong effect on the colonies size is confirmed by the decrease in colony number by $N P_{C P T}$ treatment. Indeed, while control culture presented an increase in colony number of $19 \%$, treated cultures with 5 or $10 \mu \mathrm{g} \cdot \mathrm{mL}^{-1}$ exhibited a decrease of $62 \%$ and $85 \%$, respectively after 8 days of treatment (Figure $5 \mathrm{C}$ ). The dose dependent effect of $\mathrm{NP}_{\mathrm{CPT}}$ on primary cultures established from colorectal tumor samples, is illustrated in Figure 5D which also demonstrates the significant decrease of the colonies.

A.

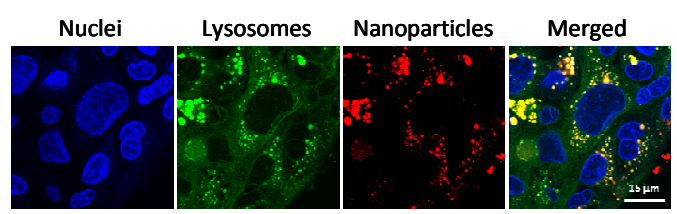

B.

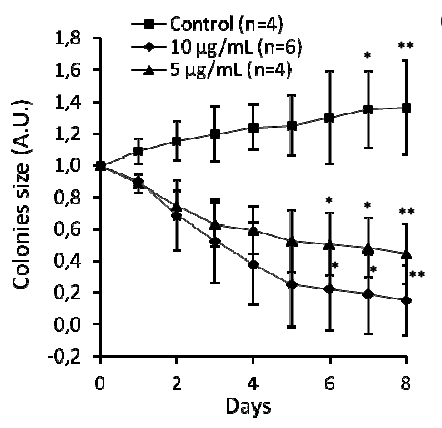

C.

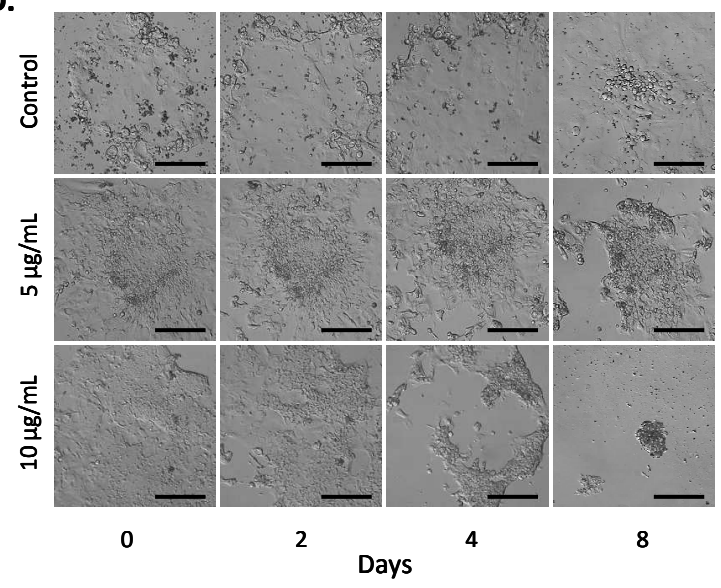

Figure 5. (A) Confocal imaging on living primary human colon cancer cells incubated $20 \mathrm{~h}$ with $\mathrm{NP}_{\mathrm{Pl}}$ at $40 \mu \mathrm{g} \cdot \mathrm{mL}^{-1}$ (scale bar $15 \mu \mathrm{m}$ ). (B) Ex-vivo human colon cancer colonies size treated or not with $\mathrm{NP}_{\text {CPT }}\left(5\right.$ or $\left.10 \mu \mathrm{g} \cdot \mathrm{mL}^{-1}\right)$ following 8 days. (C) Colonies number treated or not with NP $\mathrm{NPT}_{\text {C }}(5$ or $10 \mu \mathrm{g}$ $\mathrm{mL}^{-1}$ ) (black bars before treatment, white bars 8 days after treatment. (D) Phase contrast imaging (scale bar $100 \mu \mathrm{m}$ ). Control displays a uniform and growing cell monolayer whereas colonies treated with $\mathrm{NP}_{\text {CPT }}$ disappear along time. ${ }^{*} p<0.01$ and ${ }^{* *} p<0.001$ for treatment with $\mathrm{NP}_{\text {CPT }}$ compared to control using Student's t test.

In this study, we described the synthesis of a new type of silicabased nanocarriers with a commercially available and cheap stopper (CA) and demonstrated the effectiveness of these camptothecin-containing NPs, on colorectal cancer cells killing.
Interestingly, the in vitro experiments on HCT-116 cell line were in agreement with ex vivo experiments performed on primary cultures from patient tumor samples. We showed the strong internalization of these nanocarriers into cancer cells and the $\mathrm{pH}$-stimulation of the nanomachines allowing their cargo release. In parallel, we observed a lower efficiency on normal fibroblasts. These nanotools may offer interesting opportunities in the reduction of side effects of chemotherapy by improving first, the tumor accumulation through Enhanced Penetration and Retention effect (EPR) ${ }^{[19]}$ and secondly, the more efficient internalization in cancer cells than in normal ones.

Our on-going prospects are mainly to design new molecules that can be used as cytotoxic agent as well as stopper, and to exploit the properties of nanoparticles surface. Indeed, residual silanol functions present at the surface of the nanoparticles could be grafted with ligands for a better targeting of colorectal cancer cells. In conclusion, these results are very promising for the development of new targeted and confined chemotherapy and give the possibility to load different anticancer drugs in the same nanocarrier for a multi-therapy of colorectal cancer.

\section{Acknowledgements}

Grants from ANR P2N and Nanomis are gratefully acknowledged. We thank Montpellier RIO imaging platform for assistance in the microscopy experiments.

\section{Notes and references}

1 K. Saika, T. Matsuda, Jpn J Clin Oncol 2013, 43, 768.

2 R. A. Audisio, D. Papamichael, Nat Rev Gastroenterol Hepatol 2012, 9, 716.

3 Z. Kordatou, P. Kountourakis, D. Papamichael, Ther Adv Med Oncol 2014, 6, 128.

4 Y-S. Cho, T-J. Yoon, E-S. Jang, K. S. Hong, S. Y. Lee, O. R. Kim, C. Park, Y.-J. Kim, G.-C. Yie, K. Chang, Cancer Letters 2010, 1, 63.

5 C. Théron, A. Gallud, C. Carcel, M. Gary-Bobo, M. Maynadier, M. Garcia, J. Lu, F. Tamanoi, J. I. Zink, M. Wong Chi Man, Chemistry- A European Journal 2014, 20, 9372.

6 M. Vallet-Regi, A. Ramila, R. P. del Real, and J. PerezPariente, Chem Mater 2001, 13, 308.

7 Kresge, C. T.; Leonowicz, M. E.; Roth, W. J.; Vartuli, J. C.; Beck, J. S. Nature 1992, 359, 710.

8 G. Arrachart, C. Carcel, P. Trens, J. J. E. Moreau, M. Wong Chi Man, Chemistry- A European Journal 2009, 15, 6279.

9 L. Fertier, C. Théron, C. Carcel, P. Trens, M. Wong Chi Man, Chem Mater 2011, 23, 2100.

10 [H. Meng, M. Xue, T. Xia, Y. L. Zhao, F. Tamanoi, J. F. Stoddart, J. I. Zink, A. E. Nel, J Am Chem Soc 2010, 132, 12690.

11 K-N. Yang, Chun-Q. Zhang, W. Wang, P. C. Wang, J-P. Zhou, X-J. Liang, Cancer Biol Med 2014, 11, 34.

12 K.-N. Yang, C.-Q. Zhang, W Wang, P. C. Wang, J.-P. Zhou, X.-J. Liang, Cancer Biol. Med. 2014, 11, 34-43.

13 X. Li, T. Zhao, D. Cheng, C. Chu, S. Tong, J. Yan, Q. Y. Li, Molecules 2014, 19, 3761.

14 R. K. Shukla, Future Oncol 2013, 9, 1893.

15 S. Polo, S. Pece, P. P. Di Fiore, Curr Opin Cell Biol 2004, 16, 156. 
16 Akkari L, Grégoire D, Floc'h N, Moreau M, Hernandez C, Simonin Y, Rosenberg AR, Lassus P, Hibner U., J Hepatol 2012, 57, 1021.

17 Y. Li, L. Wang, L. Pappan, A. Galliher-Beckley, J. Shi, Mol Cancer 2012, 11, 87.

18 L. Ricci-Vitiani, D. G. Lombardi, E. Pilozzi, M. Biffoni, M. Todaro, C. Peschle, R. De Maria, Nature 2007, 445, 111.

19 Torchilin VP. Handb Exp Pharmacol 2010, 197, 3. 